\title{
Midterm results of endovascular repair of descending thoracic aortic aneurysms with first-generation stent grafts
}

Philippe Demers, MD, MSc, FRCSC

D. Craig Miller, MD

R. Scott Mitchell, MD

Stephen T. Kee, MD

Daniel Sze, MD, PhD

Mahmood K. Razavi, MD

Michael D. Dake, MD

See related editorial on page 620.
From the Department of Cardiovascular Surgery and Division of Cardiovascular and Interventional Radiology, Stanford University School of Medicine, Stanford, Calif.

Read at the Twenty-ninth Annual Meeting of the Western Thoracic Surgical Association, Carlsbad, Calif, June 18-21, 2003.

Dr Demers is supported by a Research Fellowship Award of the Heart and Stroke Foundation of Canada and is a Thelma and Henry Doelger Cardiovascular Surgical Research Scholar at Stanford University School of Medicine.

Received for publication June 17, 2003; revisions requested Oct 3, 2003; accepted for publication Oct 10, 2003.

Address for reprints: D. Craig Miller, MD, Department of Cardiothoracic Surgery, Falk Cardiovascular Research Center, Stanford University School of Medicine, Stanford, CA 94305-5247 (E-mail: dcm@ stanford.edu).

J Thorac Cardiovasc Surg 2004;127:664-73 $0022-5223 / \$ 30.00$

Copyright () 2004 by The American Association for Thoracic Surgery

doi:10.1016/j.jtcvs.2003.10.047
Objective: Five years after reporting our initial stent-graft repair of descending thoracic aortic aneurysms experience, we determined the 5- to 10-year results of stent-graft treatment and identified risk factors for adverse late outcomes.

Methods: Between 1992 and 1997, 103 patients (mean age $69 \pm 12$ years) underwent repair using first-generation (custom-fabricated) stent grafts. Sixty-two patients $(60 \%)$ were unsuitable candidates for conventional open surgical repair ("inoperable"). Follow-up was $100 \%$ complete (mean $4.5 \pm 2.5$ years; maximum 10 years). Outcome variables included death and treatment failure (endoleak, aortic rupture, reintervention, and/or aortic-related or sudden death).

Results: Overall actuarial survival was $82 \% \pm 4 \%, 49 \% \pm 5 \%$, and $27 \% \pm 6 \%$ at 1,5 , and 8 years. Survival in open surgical candidates was $93 \% \pm 4 \%$ and $78 \% \pm$ $6 \%$ and at 1 and 5 years compared with $74 \% \pm 6 \%$ and $31 \% \pm 6 \%$ in those deemed inoperable $(P<.001)$. Independent risk factors for death were older age (hazard ratio $=1.1 ; P=.008$ ), previous stroke (hazard ratio $=2.8 ; P=.003$ ), and being designated an inoperable candidate (hazard ratio $=1.9 ; P=.04$ ). Actuarial freedom from aortic reintervention and treatment failure at 8 years was $70 \% \pm 6 \%$ and $39 \%$ $\pm 8 \%$, respectively. Earlier operative year (hazard ratio $=1.2 ; P=.07$ ), larger distal landing zone diameter (hazard ratio $=1.1 ; P=.001$ ), and transposition of the left subclavian artery (hazard ratio $=3.3 ; P=.008$ ) were determinants of treatment failure.

Conclusions: Survival after aneurysm repair using crude, first-generation stent grafts was satisfactory in good operative candidates but bleak in the inoperable cohort, raising the question of whether asymptomatic patients should have even been treated. Late aortic complications were detected in many patients, reemphasizing the importance of serial imaging surveillance.

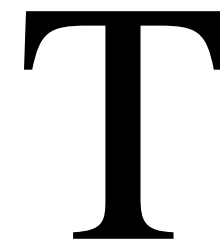

raditional treatment of patients with descending thoracic aortic aneurysms is open surgical graft replacement. ${ }^{1}$ Despite progressive surgical advances, conventional surgical repair is still associated with substantial morbidity and mortality, especially in elderly patients with other major medical conditions., ${ }^{2,3}$

Initially introduced by Dotter in $1969,{ }^{4}$ endovascular stent-graft treatment of arterial aneurysms was subsequently studied in animal models of abdominal aortic aneurysm and acute aortic dissection. ${ }^{5,6}$ Parodi and coworkers ${ }^{7}$ described the successful use of stent grafts for endovascular repair of abdominal aortic aneurysms in 1991. Our group reported the feasibility of endovascular repair of thoracic aortic aneurysms using stent grafts in $1994 .{ }^{8}$ This was followed by 
reports demonstrating that this less invasive approach was associated with low procedural morbidity and mortality and acceptable early results. ${ }^{9-16}$ The long-term durability and efficacy of stent-graft repair of thoracic aortic aneurysms, however, remains unknown.

Our prospective observational study at Stanford University Medical Center using crude first-generation, custommade stent grafts commenced in 1992; in 1998 we reported the results of our initial 5 years of experience (1992-1997) in 103 consecutive patients. ${ }^{10}$ The objectives of this current report were to assess the midterm results in this same patient cohort and to identify risk factors portending adverse late outcomes.

\section{Patients and Methods}

Between July 1992 and November 1997, 103 consecutive patients underwent transluminal endovascular stent-graft placement for repair of descending thoracic aortic aneurysms under an investigational protocol approved by the Institutional Review Board. Patient evaluation and selection, as well as the procedures, involved both cardiovascular surgeons and interventional radiologists. As discussed in previous publications, ${ }^{8,10}$ in general all patients referred with descending thoracic aortic aneurysms were considered potential candidates for stent-graft repair if they were older and not good surgical risk; those with suitable anatomic characteristics for endovascular repair and adequate vascular access were offered a stent graft. Certain younger, low-risk patients insisted on a stent graft.

\section{Patients}

Baseline clinical characteristics of the 103 patients as well as anatomic characteristics of the descending thoracic aortic aneurysms have been described previously. ${ }^{10}$ Sixty-two of the 103 patients $(60 \%)$ were judged by 1 of the surgeons to be an unsuitable candidate for conventional open surgical repair because of various comorbidities, including symptomatic coronary artery disease $(22 \%)$, congestive heart failure $(14 \%)$, chronic obstructive pulmonary disease $(31 \%)$, renal failure $(22 \%)$, previous cardiovascular operations $(45 \%)$, or other medical problems. ${ }^{10}$

\section{Preprocedural Imaging}

All patients underwent spiral computed tomographic angiography (CTA) scanning with 3-dimensional reconstruction and calibrated aortography before stent-graft placement to determine the location, length, and diameter of the aneurysm and landing zones, as well as to evaluate the suitability of the iliac and femoral arteries for vascular access. Stent-graft dimensions were calculated from the CTA images; they were oversized by $10 \%$ to $15 \%$ compared with the landing zone diameters and were at least 30 to $40 \mathrm{~mm}$ longer than the target lesions to ensure adequate wall contact and a tight circumferential seal in the landing zones.

\section{Device Details and Stent-Graft Placement}

Details of stent-graft custom fabrication and endoprosthesis insertion and deployment techniques were reported previously. ${ }^{8,10}$ In brief, first-generation stent grafts were custom-fabricated from modified self-expandable Gianturco Z stents (Cook, Bloomington, Ind) covered with a woven polyester graft (Boston Scientific Corporation, Oakland, NJ). A $22 \mathrm{~F}$ to $24 \mathrm{~F}$ delivery system (Cook) was used for deployment of the device. General anesthesia was used in all patients. Stent-graft placement was achieved by a transfemoral approach whenever feasible. An alternative vascular site was necessary in $42 \%$ of patients. ${ }^{10}$ Using fluoroscopic and transesophageal echocardiographic guidance and surgical exposure of the access artery, the sheath and dilator system was advanced over a guide wire and positioned across the target lesion. Stent grafts were then deployed after optimal positioning of the device using a pusher rod inside the sheath. When an endoleak was detected, additional procedures, such as additional stent-graft placement or coil embolization, were performed as necessary.

\section{Follow-up}

The follow-up protocol included contrast computed tomography (CT) imaging before hospital discharge, 6 months after stent-graft placement, and yearly thereafter. Because the majority of patients were not followed at Stanford, compliance with the imaging surveillance protocol was variable. At least 1 follow-up CT scan was available for $85 \%$ of patients surviving more than 1 year. Follow-up clinical status was obtained by contacting all surviving patients or family members and their primary care physician between July and December 2002 and was 100\% complete; follow-up averaged $4.5 \pm 2.5$ years (maximal follow-up $=10$ years; total cumulative follow-up $=422$ patient-years; 48 patients remaining at risk at 5 years). Cause of death was determined from death certificates, medical records, and, when available, autopsy reports.

\section{Definitions}

Primary success was defined as complete exclusion of the aneurysmal sac without any additional intervention. Secondary success was defined as complete exclusion of the aneurysm after secondary intervention. Endoleak was defined as radiological evidence of blood flow outside the stent graft and was classified as primary (diagnosed within 30 days of endovascular repair) or secondary (diagnosed more than 30 days after intervention) according to published guidelines. ${ }^{17}$ Aortic reintervention was defined as the need for any surgical or endovascular interventions on the treated aortic segment during follow-up. Treatment failure was defined as a broad, all inclusive composite end point including (1) perioperative death, (2) endoleak, (3) aortic reintervention, (4) aorticrelated death, and (5) all sudden, unexplained late deaths.

\section{Statistical Analysis}

Data are expressed as mean \pm standard deviation or as a proportion with confidence limits. The Kaplan-Meier nonparametric method was used to generate actuarial survival estimates, which are reported \pm 1 standard error (SE, approximately $70 \%$ confidence limits) and compared using the log-rank test. Actual estimates of freedom from nonfatal events were also computed, as actuarial estimates overestimate the probability of nonfatal complications. To identify independent risk factors for untoward events, a multivariable forward stepwise Cox proportional hazards model was used after exploratory analysis of 34 preoperative and perioperative variables (Appendix). The $P$ values for inclusion and retention 

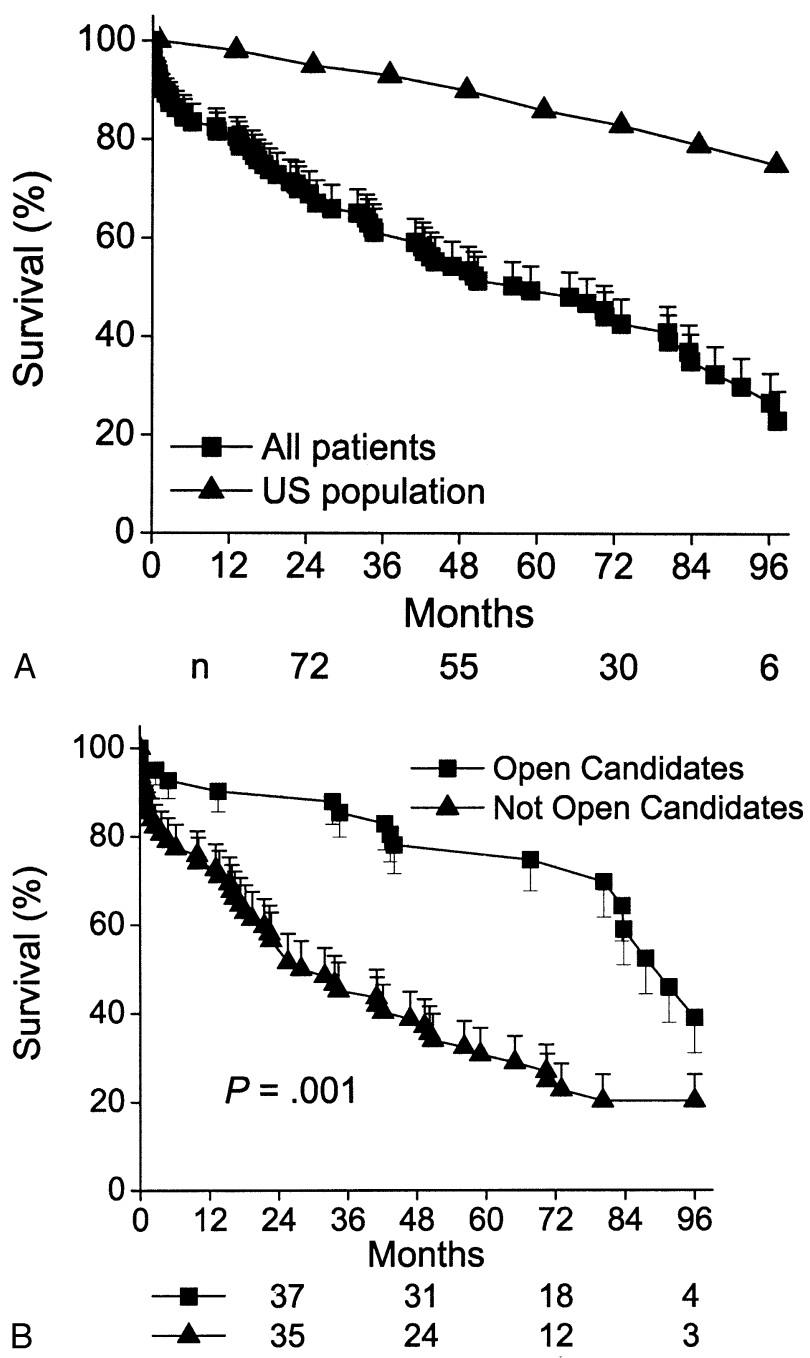

Figure 1. A, Overall actuarial survival estimates for all 103 patients ( $\pm 1 \mathrm{SE}$ ). For perspective, this graph also portrays survival curve for age- and gender-matched US population. B, Actuarial survival according to whether the patient was judged not to be a reasonable surgical candidate for open repair ( $\pm 1 \mathrm{SE}$ ).

of variables in the models were .10 and .08 , respectively, and the $\beta$ coefficients from the multivariable equation are reported. The magnitude of the clinical impact of predictive covariates on the event under consideration in the Cox model is reported as an indicator of relative risk, $\mathrm{e}^{\beta}$, or hazard ratio (HR), but this can only be strictly interpreted for dichotomous covariates. All statistical analyses were performed with the SPSS program (version 10.0, SPSS Inc, Chicago, Ill).

\section{Results}

Early Outcome

Procedural success. Perioperative mortality was $9 \% \pm$ $3 \%$. The stent graft was deployed successfully in all but 1 patient, resulting in 1 surgical conversion. The primary success rate was $73 \% \pm 5 \%$. A primary endoleak was detected in the perioperative period in 21 patients, of which 11 underwent successful secondary endovascular interventions, yielding a secondary success rate of $84 \% \pm 4 \%$. Secondary reinterventions were unsuccessful in 3 patients, and 7 patients had primary endoleaks that were not addressed.

\section{Late Outcome}

Survival. Actuarial survival estimates 1, 5, and 8 years after the procedure were $82 \% \pm 4 \%, 49 \% \pm 5 \%$, and $27 \%$ $\pm 6 \%$, respectively, for all patients (Figure $1, A$ ). As shown in Figure $1(B)$, patients judged to be reasonable surgical candidates had a significantly better life expectancy than those who were unsuitable for open operative repair $(93 \%$ $\pm 4 \%$ vs $74 \% \pm 6 \%$ at 1 year, $78 \% \pm 6 \%$ vs $31 \% \pm 6 \%$ at 5 years, and $38 \% \pm 12 \%$ vs $28 \% \pm 6 \%$ at 8 years, respectively; $P<.001$ ). Among the 9 patients who were initially discharged with an endoleak (untreated or unsuccessful secondary interventions), survival was $55 \% \pm 14 \%$ and $22 \% \pm 14 \%$ at 1 and 2 years, respectively. Causes of early and late deaths are listed in Table 1.

Reintervention. Actuarial freedom from aortic reintervention was $83 \% \pm 4 \%, 77 \% \pm 5 \%$, and $70 \% \pm 6 \%$ at 1 , 5 , and 8 years (Figure 2, $A$ ), and actual freedom from aortic reintervention was $84 \% \pm 3 \%, 80 \% \pm 4 \%$, and $78 \% \pm 4 \%$ (Figure 2, B). More specifically, actuarial freedom from repeat endovascular procedure was $83 \% \pm 4 \%, 82 \% \pm 4 \%$, and $76 \% \pm 6 \%$ at 1,5 , and 8 years, while actual freedom from repeat endovascular procedure was $84 \% \pm 3 \%, 83 \%$ $\pm 4 \%$, and $82 \% \pm 4 \%$. Actuarial freedom from aortic reoperation was $99 \% \pm 1 \%, 94 \% \pm 3 \%$, and $71 \% \pm 10 \%$ at 1,5 , and 8 years; actual freedom from aortic reoperation was $99 \% \pm 1 \%, 96 \% \pm 2 \%$, and $95 \% \pm 3 \%$.

Aortic rupture. Eleven patients sustained rupture of the treated aortic segment (6 surgical candidates and 5 considered inoperable). Rupture was fatal in 10 patients. Actuarial freedom estimates from aortic rupture were $98 \% \pm 2 \%$, $91 \% \pm 3 \%$, and $80 \% \pm 8 \%$, at 1,5 , and 8 years, respectively (Figure $3, A$ ), whereas actual freedom from aortic rupture was $98 \% \pm 1 \%, 94 \% \pm 3 \%$, and $91 \% \pm 3 \%$ (Figure $3, B)$ at these same times.

Endoleaks. Twenty-two patients developed a new (or secondary) endoleak during follow-up (proximal type I in 9, distal type I in 8, proximal and distal type I leaks in 2, type II in 2, and type III in 1). Actuarial freedom from primary or secondary endoleak was $78 \% \pm 4 \%, 64 \% \pm 5 \%$, and $50 \% \pm 9$, and actual freedom from any endoleak was $79 \%$ $\pm 4 \%, 70 \% \pm 5 \%$, and $67 \% \pm 5 \%$ at 1,5 , and 8 years. Actuarial freedom from a secondary endoleak was $98 \% \pm$ $2 \%, 81 \% \pm 5 \%$, and $60 \% \pm 10 \%$ at 1,5 , and 8 years (actual estimates were $98 \% \pm 2 \%, 89 \% \pm 3 \%$, and $84 \% \pm 4 \%$ ). 
TABLE 1. Causes of early and late deaths

\begin{tabular}{lcc}
\hline & $\begin{array}{c}\text { Early } \\
\text { deaths }\end{array}$ & $\begin{array}{c}\text { Late } \\
\text { deaths }\end{array}$ \\
\hline Acute myocardial infarction & 1 & 8 \\
Aortoesophageal fistula & 0 & 2 \\
Aortobronchial fistula & 0 & 1 \\
Abdominal aortic aneurysm rupture & 0 & 1 \\
Cancer & 1 & 9 \\
Cerebrovascular accident & 1 & 9 \\
Cirrhosis & 0 & 1 \\
Congestive heart failure & 0 & 5 \\
Diverticulitis & 0 & 1 \\
Hemorrhage & 1 & 0 \\
Ischemic colitis & 0 & 1 \\
Pneumonia & 0 & 3 \\
Pulmonary embolism & 1 & 0 \\
Renal failure & 0 & 1 \\
Respiratory failure & 1 & 1 \\
Sepsis & 2 & 2 \\
Sudden death & 0 & 7 \\
Suicide & 0 & 1 \\
Thoracic aortic aneurysm rupture & 1 & 3 \\
\hline
\end{tabular}

Treatment failure. Actuarial freedom from the overall composite end point treatment failure was $67 \% \pm 5 \%, 56 \%$ $\pm 5 \%$, and $39 \% \pm 8 \%$ at 1,5 , and 8 years, respectively (Figure 4, $A$ ), and actual freedom from treatment failure was $67 \% \pm 4 \%, 58 \% \pm 5 \%$, and $52 \% \pm 5 \%$ (Figure $4, B$ ) at the same times.

\section{Multivariable Analyses}

Mortality. Multivariable analysis revealed that increasing age $(\mathrm{HR}=1.1,95 \%$ CI 1.0-1.2, $P=.008)$, previous cerebrovascular accident $(\mathrm{HR}=2.8,95 \%$ CI 1.4-5.6, $P=$ .003 ), and being designated not an open surgical candidate $(\mathrm{HR}=2.0,95 \%$ CI 1.2-3.6, $P=.03)$ were the significant independent determinants of all (early and late) deaths (Table 2). Similarly, older age, larger thoracic aortic aneurysm maximal diameter, and presence of an abdominal aortic aneurysm were determinants of late death (Table 2).

Reintervention. As shown in Table 3, the significant independent determinants of aortic reintervention were transposition of the left subclavian artery (HR $=5.0,95 \%$ CI 1.6-15.6, $P=.006)$ and a larger proximal landing zone $(\mathrm{HR}=1.2 / \mathrm{mm}, 95 \%$ CI $1.0-1.4, P=.03)$.

Treatment failure. Cox proportional hazards model identified earlier operative year (HR $=1.2,95 \%$ CI 1.0-1.5, $P=.07)$, larger distal landing zone diameter $(\mathrm{HR}=1.1 /$ $\mathrm{mm}, 95 \%$ CI 1.0-1.2, $P=.05$ ), and transposition of the left subclavian artery ( $\mathrm{HR}=3.3,95 \% \mathrm{CI} 1.4-7.8, P=.008)$ to portend a significantly higher likelihood of treatment failure (Table 3).

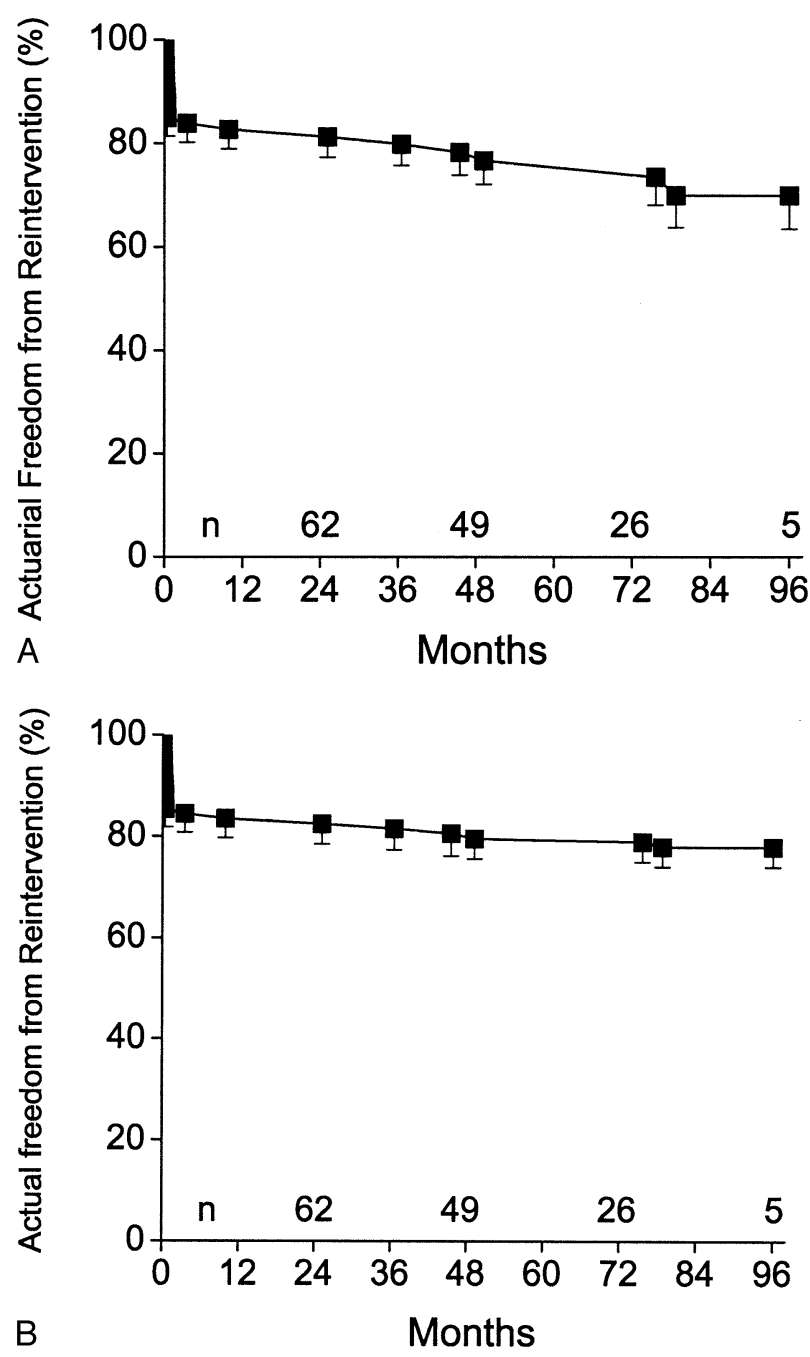

Figure 2. A, Actuarial freedom from aortic reintervention (see text for definition) for all 103 patients ( $\pm 1 \mathrm{SE}$ ). B, Actual freedom from aortic reintervention ( $\pm 1 \mathrm{SE})$.

\section{Discussion}

Thoracic aortic aneurysm is a life-threatening condition with an estimated incidence of 6 to 10 cases per 100,000 person-years. ${ }^{18}$ Although less common than aortic dissection, the prevalence of thoracic aortic aneurysms appears to be increasing ${ }^{19}$; whether this is a real phenomenon as the population ages or predominately just a reflection of advances in noninvasive diagnostic imaging is not known. The natural history of untreated patients with thoracic aortic aneurysms is characterized by progressive expansion and eventual rupture ${ }^{18-21} ; 5$-year survival in patients with unoperated thoracic aortic aneurysms has been estimated to range from $15 \%$ to $55 \% .{ }^{18,19,21}$ Although open surgical graft replacement is the traditional treatment for these patients, the presence of many medical comorbidities in this specific patient population increases the surgical risks, 


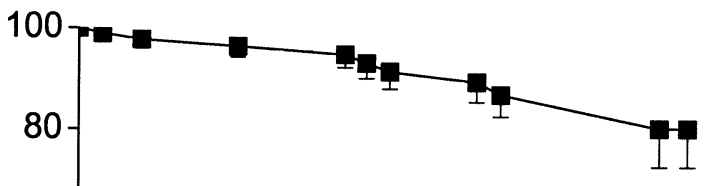

A

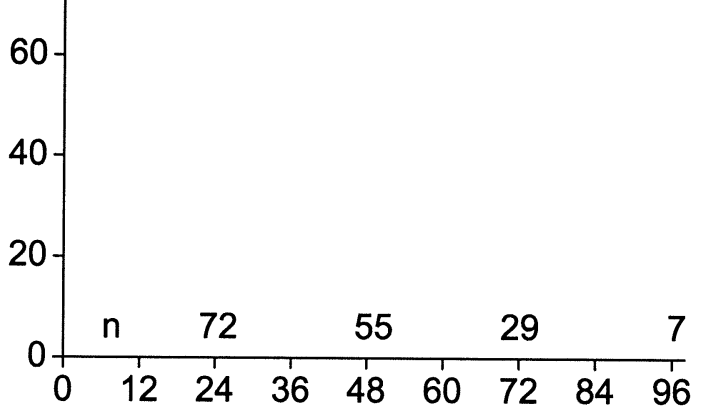

Months

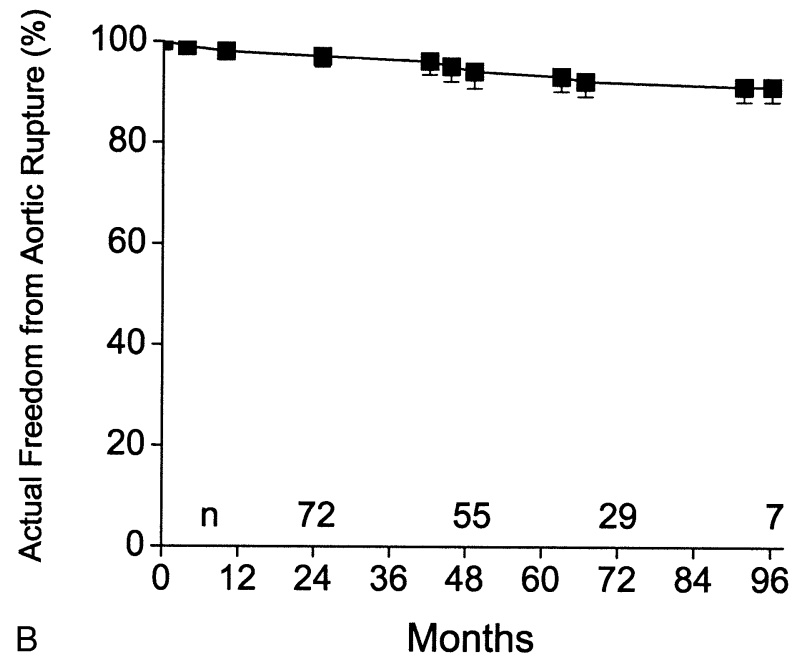

Figure 3. A, Actuarial freedom from rupture of the treated aortic segment for all 103 patients ( $\pm 1 \mathrm{SE}$ ). $B$, Actual freedom from aortic rupture $( \pm 1 \mathrm{SE})$.

especially in cases of emergency operation for aortic rupture., ${ }^{2,22-24}$ Nevertheless, 5-year survival rates between $60 \%$ and $80 \%$ have been achieved in recent surgical series. ${ }^{2-3,22-23}$

Endovascular stent-graft repair of descending thoracic aortic aneurysms started at Stanford in 1992 as a less invasive alternative to conventional open surgical graft replacement. ${ }^{8,10}$ In early reports, stent-graft treatment was usually reserved for poor candidates for open operation. ${ }^{8-11}$ After the safety of this procedure and evidence of acceptable short-term results were demonstrated, use of stent grafts progressively expanded to other patients and other thoracic aortic pathologies. ${ }^{13-16}$ Despite encouraging earlyterm results and increasing enthusiasm for this new technology, only 1 study has been published describing the 5- to

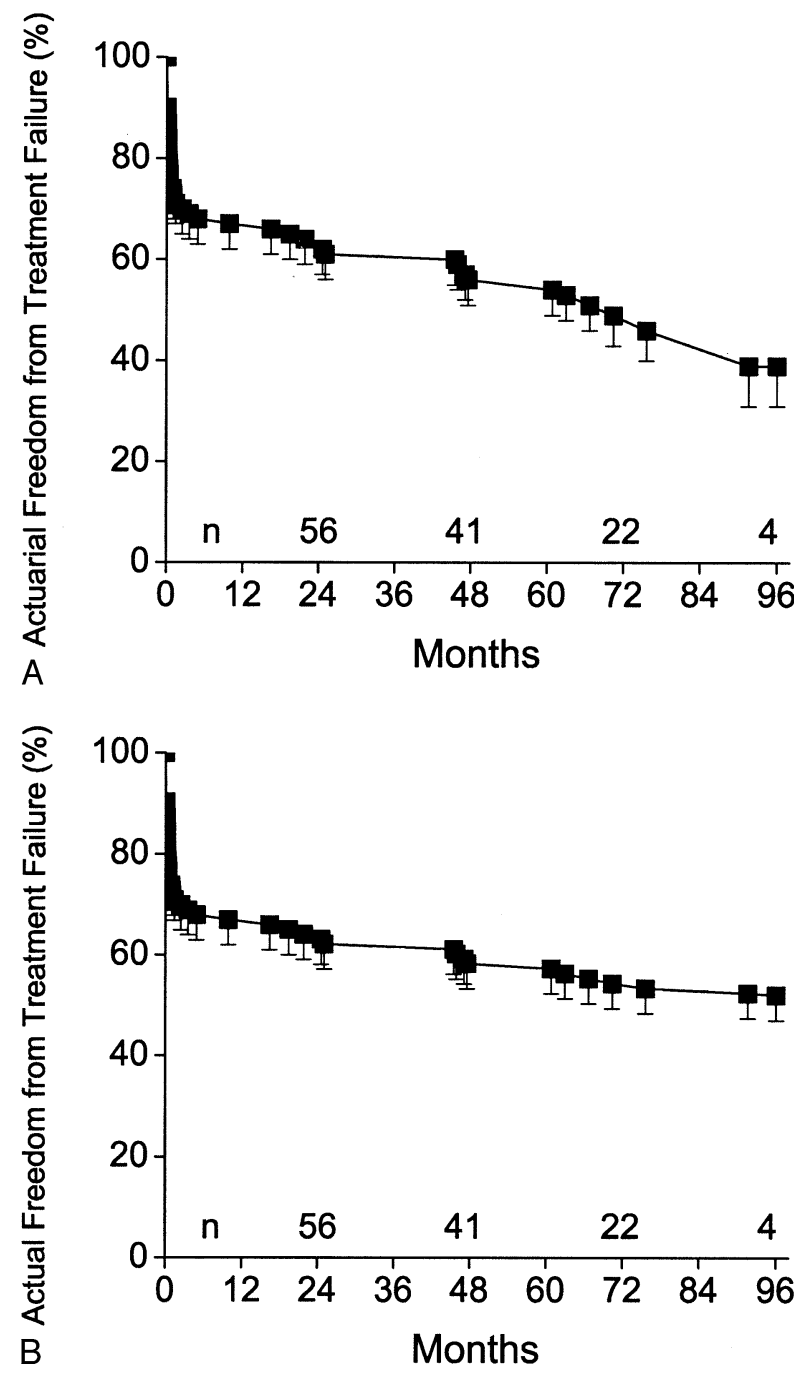

Figure 4. A, Actuarial freedom from treatment failure (see text for definition) in all 103 patients ( $\pm 1 \mathrm{SE}$ ). $B$, Actual freedom from treatment failure ( $\pm 1 \mathrm{SE})$.

10-year results of endovascular stent-graft repair of abdominal aortic aneurysms (AAA), ${ }^{25}$ and no such data exist for patients with thoracic aortic aneurysms. Therefore, this current analysis of the midterm stent-graft effectiveness to determine whether stent grafting provides lasting protection from aneurysm expansion or rupture was performed before broadening the indications for endovascular stent-graft treatment in other patients with thoracic aortic aneurysms. ${ }^{26}$

\section{Specific Findings of This Study}

In this cohort of 103 patients who underwent endovascular stent-graft repair of thoracic aortic aneurysms using firstgeneration devices (62 of which were judged not to be reasonable operative candidates), perioperative mortality was $9 \% \pm 3 \%$, which is comparable to contemporary sur- 
TABLE 2. Independent risk factors for early and late deaths after endovascular repair of descending thoracic aortic aneurysms with first-generation stent grafts according to multivariable Cox proportional-hazards model

\begin{tabular}{|c|c|c|c|c|}
\hline \multirow[b]{2}{*}{ Variable } & \multicolumn{3}{|c|}{ Hazard } & \multirow{2}{*}{$\begin{array}{c}P \\
\text { value }\end{array}$} \\
\hline & $\boldsymbol{\beta}$ & ratio & $95 \% \mathrm{Cl}$ & \\
\hline \multicolumn{5}{|l|}{ Early and late deaths } \\
\hline Age (increasing) & 0.04 & 1.1 & $1.0-1.2$ & .008 \\
\hline Previous CVA & 1.03 & 2.8 & $1.4-5.6$ & .003 \\
\hline Not an open candidate & 0.64 & 2.0 & $1.1-3.5$ & .04 \\
\hline \multicolumn{5}{|l|}{ Late deaths } \\
\hline Age (increasing) & 0.06 & 1.1 & $1.0-1.2$ & .001 \\
\hline Aneurysm diameter (larger) & 0.03 & 1.1 & $1.0-1.2$ & .001 \\
\hline Abdominal aortic aneurysm & 0.64 & 1.9 & $1.1-3.3$ & .02 \\
\hline
\end{tabular}

CVA, Cerebrovascular accident.

gical series. Primary and secondary technical success rates were $73 \%$ and $84 \%$, respectively. Paraplegia and cerebrovascular accident occurred in $3 \%$ and $7 \%$ of patients, respectively. ${ }^{10}$ The stroke problem highlights 1 of the main drawbacks of the primitive, first-generation devices used in this early experience, which required manipulation of large and stiff introducers and delivery sheaths in the diseased ascending aorta and transverse arch.

Overall, survival at 1,5 , and 8 years was $82 \%, 49 \%$, and $27 \%$, respectively, which was considerably lower than the expected survival for a population matched for age and gender. Late survival in good surgical candidates (78\% at 5 years) was satisfactory and comparable to contemporary results after conventional open surgical treatment. ${ }^{2-3,22,23}$ In patients judged not to be suitable open surgical candidates, however, life expectancy was bleak ( $31 \%$ survival at 5 years) due mainly to death caused by coexistent diseases. This finding raises the important philosophical question of whether endovascular treatment should be offered to these patients if they are asymptomatic. In these sick individuals the risks of endovascular stent-graft repair may exceed the risk inherent in just watching and waiting. Furthermore, stent grafting does nothing to enhance the quality of life of these ill patients. Based on data from the large EUROSTAR AAA multicenter registry, more than $20 \%$ of high-risk patients died within 1 year of endovascular stent-graft AAA repair. ${ }^{27}$ They concluded that patients unfit for open operation or general anesthesia probably did not benefit from endovascular AAA repair.

Multivariable analysis identified increasing age, previous cerebrovascular accident, and being designated not an open surgical candidate as independent determinants of (combined early and late) death, while increasing age, increasing aneurysm diameter, and concomitant abdominal aortic aneurysm were determinants of late death. These factors emphasize the importance of careful patient selection and
TABLE 3. Independent risk factors for reintervention and treatment failure after endovascular repair of descending thoracic aortic aneurysms with first-generation stent grafts according to multivariable Cox proportional-hazards model

\begin{tabular}{|c|c|c|c|c|}
\hline Variable & $\boldsymbol{\beta}$ & $\begin{array}{c}\text { Hazard } \\
\text { ratio }\end{array}$ & $95 \% \mathrm{CI}$ & $\begin{array}{c}P \\
\text { value }\end{array}$ \\
\hline \multicolumn{5}{|l|}{ Reintervention } \\
\hline $\begin{array}{l}\text { Proximal landing zone } \\
\text { (larger) }\end{array}$ & 0.13 & 1.2 & $1.0-1.4$ & .03 \\
\hline Transposition LSCA & 1.61 & 5.0 & $1.6-15.6$ & .006 \\
\hline \multicolumn{5}{|l|}{ Treatment failure } \\
\hline Operative year (earlier) & 0.21 & 1.2 & $1.0-1.5$ & .07 \\
\hline $\begin{array}{l}\text { Distal landing zone } \\
\text { (larger) }\end{array}$ & 0.09 & 1.1 & $1.0-1.2$ & .001 \\
\hline Transposition LSCA & 1.18 & 3.3 & $1.4-7.8$ & .008 \\
\hline
\end{tabular}

LSCA, Left subclavian artery.

anatomic factors in determining who is a good candidate for stent grafting.

The longer duration of follow-up reported herein allowed detection of several late complications that were not evident in previous publications. ${ }^{10-15}$ Overall, actuarial freedom from treatment failure (perioperative death, endoleaks, aortic reintervention, aortic-related deaths, or sudden, unexplained late deaths) was $67 \%, 56 \%$, and $39 \%$ at 1,5 , and 8 years. Actuarial freedom from primary or secondary endoleak was $78 \%, 64 \%$, and $50 \%$ at 1,5 , and 8 years, while actuarial freedom from aortic reintervention was $83 \%, 77 \%$, and $70 \%$, respectively, at these same times.

The only determinants of reintervention were transposition of the left subclavian artery (LSCA) and a larger proximal landing zone diameter, while earlier operative year, transposition of the LSCA, and a larger distal landing zone diameter were independent risk factors for treatment failure. These factors reflect the impact of our learning curve, increasing experience, and better patient selection criteria over time on stent-graft repair durability, as well as the importance of anatomic factors such as favorable landing zone morphology (small, minimally angulated, cylindrical landing zones of adequate length). The necessity for transposition of the LSCA was probably a surrogate reflecting suboptimal proximal landing zone pathological anatomy.

One noteworthy finding in this study was the relatively high incidence of late rupture of the treated aortic segment, which occurred exclusively in patients with documented endoleaks; the estimate of freedom from late aortic rupture was $91 \%$ at 5 years and $80 \%$ at 8 years. This is sobering, as open surgical graft replacement usually is associated with a durable long-term result with only a negligible late hazard of anastomotic problems or aortic rupture. These results clearly indicate that endovascular stent-graft repair using 
primitive, first-generation devices was palliative for the most part.

Most of the endoleaks detected during follow-up were related to the proximal or distal landing zones, or type I endoleaks. ${ }^{17}$ Endoleaks, especially type I, are associated with persistent or recurrent aneurysmal sac pressurization, progressive expansion, and eventual rupture. ${ }^{25,28,29}$ This serious complication of endovascular stent-graft repair should be actively looked for during follow-up and treated aggressively when found. Multiple factors may have contributed to these late endoleaks; inadequate fixation allowing stent-graft migration has been proposed as 1 factor contributing to the development of a secondary endoleak. $^{28,29}$ In this study, significant device migration was not observed on imaging studies during follow-up, even in patients developing secondary endoleaks. Poor landing zone morphology (larger diameter, short length, abrupt angulation, presence of thrombus), vector forces acting on the endoprosthesis, ${ }^{29}$ or cantilevering the proximal stent graft end off the lesser curve of the distal arch are other factors that may play a role in endoleak formation. Finally, disease progression proximally or distally, especially in patients with diffuse degenerative aneurysms, may result in slow enlargement of the landing zones, loss of fixation, and sac pressurization.

\section{Midterm Results of Endovascular Stent-Graft Repair in the Literature}

The initial results of endovascular stent-graft treatment of thoracic aortic aneurysms have been reported, but the average follow-up interval was only 9 to 22 months. $^{10,13-15,29}$ Stent grafting was fairly safe, but durability has not been determined. Because certain complications, such as late endoleaks, may not occur until 3 to 5 years afterward as the aortic landing zones slowly but inexorably enlarge, ${ }^{25,30}$ previous reports may have underestimated complication rates. Orend and associates ${ }^{15}$ analyzed a 6-year experience with thoracic aortic stent-graft repair in 74 patients; 1 of 5 late deaths was related to stent graft, and 5 patients (7\%) required reinterventions for late aortic complications at an average of 22 months postprocedure. Other investigators, however, have reported a higher incidence of stent-graft complications. Among 23 patients treated with custommade stent grafts and followed with a strict imaging protocol (median of 18 months), Resch and collaborators ${ }^{29}$ observed 5 late type I endoleaks (22\%), and migration of at least 1 end of a stent graft was documented in 10 patients, or $43 \%$. Recently, late results of endovascular AAA repair using first-generation stent grafts (median follow-up was 6 years) were reported: Alric and colleagues ${ }^{25}$ observed that the actuarial estimate of freedom from AAA-related death was only $73 \%$ at 7 years. Actuarial freedom estimates from endoleak and surgical conversion were $49 \%$ and $50 \%$, re- spectively, at 7 years. Despite the small number of patients $(n=23)$, these authors concluded that endovascular repair of AAA using first-generation stent grafts was associated with suboptimal durability and failed to protect patients from AAA-related death. ${ }^{25}$ Our observations reported herein for thoracic aortic stent grafting can be interpreted similarly; hopefully, more refined patient selection criteria and improved stent-graft devices in the future will be associated with more overall patient benefit.

\section{Clinical Implications}

First, until longer follow-up in more patients becomes available to learn definitively just how durable stent grafting is using new commercial devices, we believe it is not prudent to offer endovascular stent-graft repair to younger patients who do not have major contraindications to open surgical repair. Second, careful selection of patients for endovascular stent grafting is key, with particular emphasis placed on identification of favorable anatomic targets, symptom status, and projected life expectancy. Third, patients with connective tissue disorders, such as the Marfan syndrome, were not included in this study and should not be treated with endovascular stent grafts due to the thin, weak aorta that theoretically predisposes them to a high likelihood of developing a false aneurysm or endoleak at the proximal or distal landing zones

Last, we can broach, but cannot definitively answer, the philosophical question each individual physician must address and the ethical question society must face concerning whether stent grafting should be withheld in elderly patients with asymptomatic aneurysms who are not open operative candidates given the very poor survival rates reported herein. The soberingly dismal life expectancy in patients not judged suitable for open surgical repair cannot be blamed on the first-generation devices used; this is a direct reflection of patient selection criteria. What we do know is that stent grafting in asymptomatic patients does not improve quality of life; indeed, a cynic would term this "futile therapy" and submit that preventing aneurysm rupture by stent grafting only prolongs patient suffering due to their multiple other debilitating medical diseases. Just because we can treat does not necessarily mean we should treat. Society, and specifically health care policy planners and payors, must grapple with these tough philosophical and ethical questions when these devices are considered for clinical release.

\section{Limitations}

Several factors restrict the inferences that can be drawn from these observations. First, the design of this prospective observational study and the lack of a randomized or concurrent control group precluded direct comparison with results achieved after conventional open surgical graft re- 
placement. Also, it is important to note that we did not have another control group of patients matched to the "inoperable" cohort who did not undergo any treatment of their aneurysm; hence, we cannot state that these ill patients actually lived any longer after stent grafting. It is unlikely that stent grafting prolonged their lives, however, given their high attrition rate over the first 3 to 5 years and the fact that so few deaths were due to aortic complications.

Second, this series represents our earliest 5-year experience with endovascular stent grafts using primitive devices in a rapidly evolving field. For example, in the initial years benign-appearing endoleaks seen on an initial study were left untreated. This mistake was soon rectified, with all possible interventional options exercised to eliminate these leaks before the patient left the hospital. Also, patient selection criteria changed over time. We now believe that endovascular stent grafting should be restricted mostly to high surgical risk, elderly patients who ideally have focal anatomic lesions associated with small, minimally angulated, cylindrical proximal and distal landing zones of sufficient length. Adequate vascular access, in terms of arterial size and lack of excessive tortuosity and occlusive disease, also needs to be considered. Due to rapidly evolving technology, the results reported herein using very crude and cumbersome first-generation devices does not represent what might potentially be achieved today using commercial third-generation devices designed specifically for the thoracic aorta. Our results reflect our earliest clinical experience using very primitive stent grafts and therefore should be considered a "worst case" scenario, as well as an analysis of a "moving target." Improved delivery systems (smaller, not sheath-pusher rod deployed, coaxial over the wire, sheath limited to the abdominal aorta) and device design (flexibility to accommodate angulated distal arch anatomy, improved fixation mechanisms, strengthened integrity, and flexible optional features with specific characteristics according to various indications) should be associated with better outcomes in the future.

Third, the absence of autopsy confirmation in all patients who died makes it difficult to substantiate the fact that stent-graft repair prevented aneurysm rupture; to avoid underestimating such possible fatal complications, we included all late, unexplained sudden deaths in the treatment failure composite end point. Even though this approach will probably overestimate the incidence of complications, we urge that this very conservative reporting definition be applied to all trials of stent grafting as it will eliminate interinstitutional bias and reporting variability. Finally, this study is limited by incomplete systematic, serial imaging follow-up and unknown medical compliance after hospital discharge; more specifically, late imaging studies were not performed in $15 \%$ of patients for a variety of reasons.

\section{Conclusion}

In this cohort of 103 patients, 5-year survival after repair of descending thoracic aortic aneurysms using first-generation stent grafts was satisfactory in operative candidates but inferior to a matched US population. Furthermore, the prognosis of those deemed inoperable was very bleak; these patients died primarily from other medical diseases and not aortic rupture. These results raise the philosophical question if any treatment at all should have been be offered to sick, elderly individuals if they had asymptomatic aneurysms. Late complications in the treated thoracic aortic segment were detected in a substantial proportion of patients, emphasizing the importance of indefinite, long-term serial imaging surveillance. Better clinical results can be expected in the future given the rapid technological advances occurring in this field.

We thank our colleagues in Cardiovascular Surgery and Interventional Radiology for allowing us to include their patients.

\section{References}

1. DeBakey ME, McCollum CH, Graham JM. Surgical treatment of aneurysms of the descending thoracic aorta: long-term results in 500 patients. J Cardiovasc Surg (Torino). 1978;19:571-6.

2. Moreno-Cabral CE, Miller DC, Mitchell RS, Stinson EB, Oyer PE, Jamieson SW, et al. Degenerative and atherosclerotic aneurysms of the thoracic aorta. J Thorac Cardiovasc Surg. 1984;88:1020-32.

3. Kouchoukos NT, Dougenis D. Surgery of the thoracic aorta. $N$ Engl J Med. 1997;336:1876-88.

4. Dotter CT. Transluminally-placed coilspring endarterial tube grafts: long-term patency in canine popliteal artery. Invest Radiol. 1969;4: 328-32.

5. Balko A, Piasecki GJ, Shah DM, Carney WI, Hopkins RW, Jackson BT. Transfemoral placement of intraluminal polyurethane prosthesis for abdominal aortic aneurysm. J Surg Res. 1986;40:305-9.

6. Moon MR, Dake MD, Pelc LR, Liddell R, Castro LJ, Mitchell RS, et al. Intravascular stenting of acute experimental type B dissections. J Surg Res. 1993;54:381-8.

7. Parodi JC, Palmaz JC, Barone HD. Transfemoral intraluminal graft implantation for abdominal aortic aneurysms. Ann Vasc Surg. 1991; 5:491-9.

8. Dake MD, Miller DC, Semba CP, Mitchell RS, Walker PJ, Liddell RP. Transluminal placement of endovascular stent-grafts for the treatment of descending thoracic aortic aneurysms. N Eng J Med. 1994;331: 1729-34.

9. Grabenwoger M, Hutschala D, Erhlich MP, Cartes-Zumelzu F, Thurnher S, Lammer J, et al. Endovascular stent graft repair for aneurysms of the descending thoracic aorta. Ann Thorac Surg. 1998;66:19-25.

10. Dake MD, Miller DC, Mitchell RS, Semba CP, Moore KA, Sakai T. The first generation of endovascular stent grafts for patients with aneurysms of the descending thoracic aorta. $J$ Thorac Cardiovasc Surg. 1998;116:689-704.

11. Greenburg R, Resch T, Nyman U, Lindh M, Brunkwall J, Brunkwall $\mathrm{P}$, et al. Endovascular repair of descending thoracic aortic aneurysms: an early experience with intermediate-term follow-up. J Vasc Surg. 2000;31:147-56.

12. Grabenwoger M, Hutschala D, Erhlich MP, Cartes-Zumeszu F, Thurnher S, Lammer J, et al. Thoracic aortic aneurysms: treatment with endovascular self-expandable stent grafts. Ann Thorac Surg. 2000;69: 441-5.

13. White RA, Donayre CE, Walot I, Lippmann M, Woody J, Lee J, et al. Endovascular exclusion of descending thoracic aortic aneurysms and chronic dissections: initial clinical results with the AneurRx device. $J$ Vasc Surg. 2001;33:927-34. 
14. Cambria RP, Brewster DC, Lauterbach SR, Kaufman JL, Geller S, Fan $\mathrm{CM}$, et al. Evolving experience with thoracic aortic stent graft repair. J Vasc Surg. 2002;35:1129-36.

15. Orend KH, Scharrer-Palmer R, Kapfer X, Kotsis T, Gorich J, SunderPlassmann L. Endovascular treatment in diseases of the descending thoracic aorta: 6-year results of a single center. J Vasc Surg. 2003;37: 91-9.

16. Dake MD. Endovascular stent-graft management of thoracic aortic diseases. Eur J Radiol. 2001;39:42-9.

17. Chaik of EL, Blankensteijn JD, Harris PL, White GH, Zarins CK, Bernhard VM, et al. Reporting standards for endovascular aortic aneurysm repair. J Vasc Surg. 2002;35:1048-60.

18. Bickerstaff LK, Pairolero PC, Hollier LH, et al. Thoracic aortic aneurysms: a population-based study. Surgery. 1982;92:1103-8.

19. Clouse WD, Hallett JW, Schaff HV, Gayari MM, Ilstrup DM, Melton LJ. Improved prognosis of thoracic aortic aneurysms. A populationbased study. JAMA. 1998;280:1926-9.

20. Juvonen T, Ergin MA, Galla JD, Lansman SL, Nguyen KH, McCullough JN, et al. Prospective study of the natural history of thoracic aortic aneurysms. Ann Thorac Surg. 1997;63:1533-45.

21. Davies RR, Goldstein LJ, Coady MA, Tittle SL, Rizzo JA, Kopf GS, et al. Yearly rupture or dissection rates for thoracic aortic aneurysms: simple prediction based on size. Ann Thorac Surg. 2002;73:17-28.

22. Svensson LG, Crawford ES, Hess KR, Coselli JS, Safi HJ. Variables predictive of outcome in 832 patients undergoing repairs of the descending thoracic aorta. Chest. 1993;104:1248-53.

23. Kouchoukos NT, Masetti P, Rokkas CK, Murphy SF, Blackstone EH. Safety and efficacy of hypothermic cardiopulmonary bypass and circulatory arrest for operations on the descending thoracic and thoracoabdominal aorta. Ann Thorac Surg. 2001;72:699-708.

24. Estrera AL, Rubenstein FS, Miller CC, Huynh TT, Letsou GV, Safi HJ. Descending thoracic aortic aneurysm: surgical approach and treatment using the adjuncts cerebrovascular fluid drainage and distal aortic perfusion. Ann Thorac Surg. 2001;72:482-6.

25. Alric P, Hinchliffe RJ, Wenham PW, Whitaker SC, Chuter TAM, Hopkinson BR. Lessons learned from the long-term follow-up of a first-generation aortic stent-graft. J Vasc Surg. 2003;37:367-73.

26. Chuter TAM. Endovascular aneurysm repair with the AneuRx stentgraft is safe, but is it effective? J Am Coll Cardiol. 2001;38:1047-8.

27. Laheij RJ, van Marrewijk CJ. Endovascular stenting of abdominal aortic aneurysm in patients unfit for elective open surgery. Lancet. 2000;356:832.

28. Harris PL, Vallabhaneni SR, Desgranges P, Becquemin JP, van Marrewijk C, Laheij RJ. Incidence and risk factors of late rupture, conversion, and death after endovascular repair of infrarenal aortic aneurysms: the EUROSTAR experience. European collaborators on stentgraft techniques for aortic aneurysm repair. J Vasc Surg. 2000;32:73949.

29. Resch T, Koul B, Dias NV, Lindblad B, Ivancev K. Changes in aneurysm morphology and stent-graft configuration after endovascular repair of aneurysms of the descending thoracic aorta. J Thorac Cardiovasc Surg. 2001;122:47-52.

30. Holaenbein TJ, Kretschmer G, Thurnher S, Schoder M, Aslim E, Lammer J, et al. Midterm durability of abdominal aortic aneurysm endograft repair: a word of caution. J Vasc Surg. 2001;33:S46-54.

\section{Discussion}

Dr H. Storm Floten (Portland, Ore). I would like to thank Dr Demers and compliment his Stanford colleagues on a very fine report. You can always count on a class act paper out of that very fine institution.

Now I have never put one of these things in and I have had absolutely no experience with this. Basically I like to operate on thoracic aneurysms, so I hope that I will try to be unbiased in my comments. However, there are a few points that should not be taken lightly, including the procedure mortality of $9 \%$, the 11 patients who died of late rupture, and obviously the inoperable patients with a 5 -year survival rate of $30 \%$. The authors have very
APPENDIX. Preoperative, anatomic, and operative variables examined as potential independent risk factors for adverse outcomes in the multivariable analyses

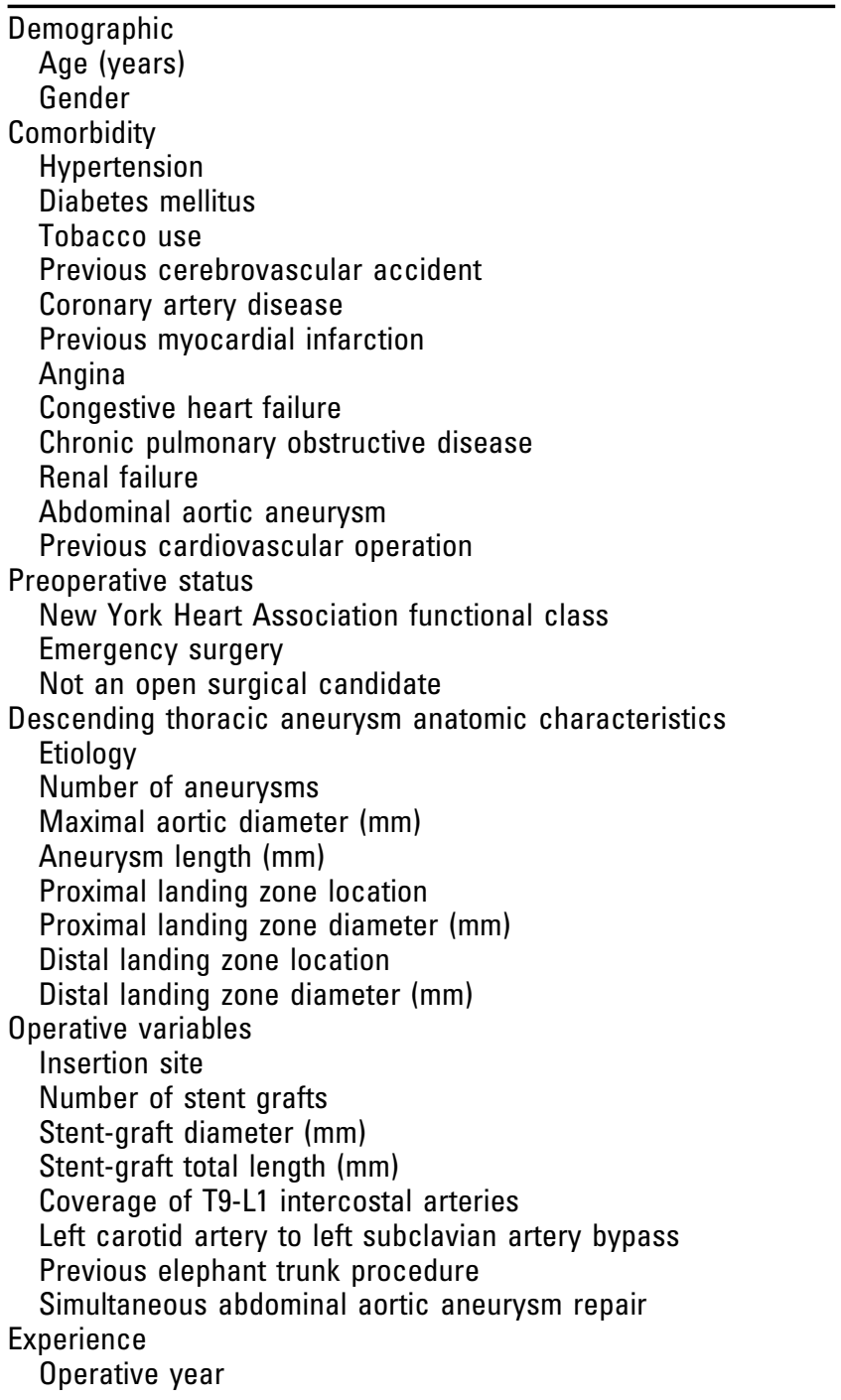

candidly and fairly addressed these issues. Now surgeons such as myself like to compare these data with our surgical results and that's a little bit difficult here. The inoperable patients may have been operable if the stent was not available. We all push the envelope on operability. This changes the cohort of patients being examined in a study like this versus our surgical results. For example, the surgical result for descending thoracic aneurysm repair is about $80 \%$ 5-year survival and in the good patients in this series it is about $80 \%$ survival, so it is misleading when you add in the inoperable patients. The patient with a cancer in the lung who dies of lung cancer 6 months later certainly does put a negative twist on this.

In my opinion, when I operate on thoracic aneurysms, it is rare that I see a nice saccular aneurysm with a perfectly clean aorta on one end and a perfectly clean aorta on the other end. The perfect example was the picture that we saw here today. On the dye study 
it looked like an absolutely normal aorta upstream and an absolutely normal downstream but I forget what it was, 2 or 3 years later, we have a problem downstream with aorta enlarging, and we know that the pathology of the aorta is always much greater than the CT scan, magnetic resonance imaging, or the dye study shows. Most of the aneurysms I operate on have a calcified arch that I am dealing with or down at the diaphragm an aneurysm that is running through the diaphragm; there is clot, there is a double-barrel lumen fusiform aneurysm related to dissection. So I don't believe that this technology will ever do away with surgical repair of descending thoracic aneurysms, but with increased improvement in selection of patients and with increased improvement in technology of the stents, I think there is a bright future for a small window of patients in whom we will be able to do this.

I really have 1 question. We all have met the 75-year-old grandma in the middle of the night who is hypertensive with an acute type III dissection and we usually treat these medically and 3 days later we are called because now she has a big pleural effusion and she is leaking. We all know that our surgical results are dismal in this setting. Have you had any experience, $\mathrm{Dr}$
Demers, or plans for any experience in dealing with this in a prophylactic situation? It seems to me if there is a great asset to this technology it would be in this patient in which we could prophylactically put a stent in the location of the tear, which is somewhere around the takeoff of the left subclavian, and protect these people from ending up on the operating table 2 or 3 days later.

Dr Demers. Thank you, Dr Floten, for your nice comments. Very few patients with acute or chronic type B dissection were included in this series, so I cannot directly answer your question with our data. We certainly don't have experience at Stanford with stent-graft treatment of uncomplicated acute type B dissections. We try to treat all uncomplicated acute type B dissections medically and will consider surgical or endovascular treatment for complicated cases. However, I am aware of a multicenter European trial comparing endovascular stent-graft treatment versus medical therapy conducted right now in Europe by Dr Nienaber from Germany. They also have another trial comparing surgical therapy versus stent-graft repair in patients with complicated dissections, so hopefully these trials will answer some of these questions.

Access to The Journal of Thoracic and Cardiovascular Surgery Online is reserved for print subscribers!

Full-text access to The Journal of Thoracic and Cardiovascular Surgery Online is available for all print subscribers. To activate your individual online subscription, please visit The Journal of Thoracic and Cardiovascular Surgery Online, point your browser to http://www.mosby.com/jtcvs, follow the prompts to activate your online access, and follow the instructions. To activate your account, you will need your subscriber account number, which you can find on your mailing label (note: the number of digits in your subscriber account number varies from 6 to 10). See the example below in which the subscriber account number has been circled:

\section{Sample mailing label}

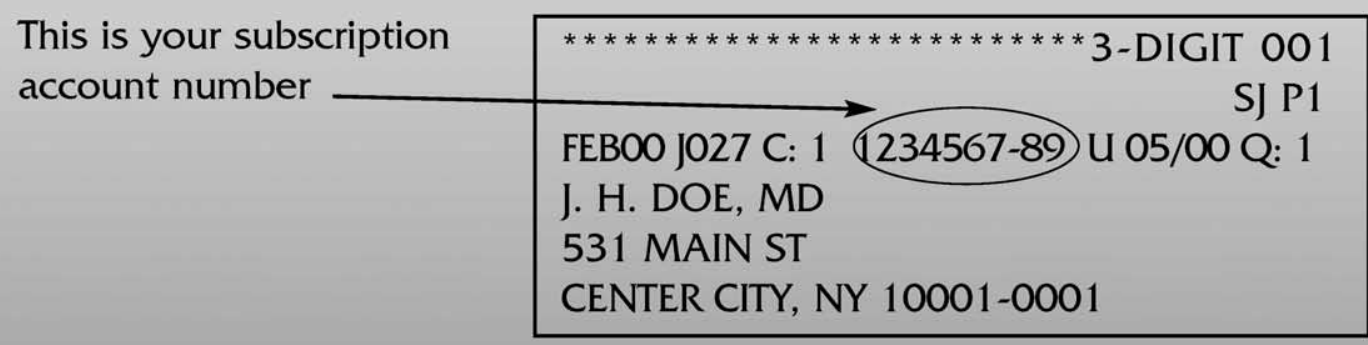

Personal subscriptions to The Journal of Thoracic and Cardiovascular Surgery Online are for individual use only and may not be transferred. Use of The Journal of Thoracic and Cardiovascular Surgery Online is subject to agreement to the terms and conditions as indicated online. 